\title{
Grazing Methods: A Viewpoint
}

\section{By Mort Kothmann}

$\checkmark$ razing management has long been a central focus of rangeland management and research. However, a communication gap exists between some managers and researchers. Voisin ${ }^{1}$ stated that the art of applied grazing management exceeded the current level of science. Some managers continue to hold this opinion. Scientists base their conclusions on replicated research of fixed treatments, while managers develop their practices through much trial and error (e.g., adaptive management) without controls or replication. This difference, in source and perspective of "facts," produces a communication gap between researchers and practitioners. While scientists may see themselves as the final filter through which defined practices might become acceptable and sustainable, managers commit to developing a program that "works" on their property.

Recent publications highlight this communication gap. Briske et al. concluded, "Continued advocacy for rotational grazing as a superior strategy of grazing on rangelands is founded on perception and anecdotal interpretations, rather than an objective assessment of the vast experimental evidence." 2 Pat Pfiel stated, "I've applied rotational-grazing principles to the properties we've managed and shown it works well."' Frank Price, describing the development of his grazing management over the past 30 years, stated, "The biggest problem for me is that I can never come up with a grazing plan that I can stay with-I am continually changing grazing rotations, time, and stock numbers... But that is one of the reasons that this program works. It is not a system. It is a continually changing program that moves with the weather, livestock and markets." ${ }^{4}$

Scientists and ranchers need to improve their communications. Briske et al. state, “... management commitment and ability are the most pivotal components of grazing system effectiveness and ... grazing systems do not possess unique properties that enable them to compensate for ineffective management..."2 In my opinion, ranchers using various rotational grazing methods agree with that statement. The key ingredient to success is "management" that applies principles adaptively, rather than a fixed "system." Research applies grazing as "treatments" (e.g., fixed grazing schedules, stocking rates, and management) to avoid confounding "grazing management" with other variables. On the other hand, ranchers view grazing schedules and stocking rates as variables to be integrated adaptively with other management practices to meet a variety of objectives. Ranchers evaluate the success of grazing management within the context of total system performance and goals, not just plant and animal production in response to fixed grazing treatments.

This paper focuses on two primary grazing management objectives for rangelands: 1) restoring and maintaining healthy rangelands, and 2) animal production. Three general grazing methods, continuous stocking, deferred stocking, and rotational stocking, are described and discussed with respect to vegetation responses and animal production. I do not believe that there is a "best" grazing method. My objective is to frame the discussion of grazing methods in a broad context and to provide some key concepts that managers can selectively utilize as they develop their grazing program. I invite scientists to view these concepts and principles as hypotheses and to design research to test them in adaptive models.

\section{Measuring Success \\ Key Concept: Evaluating grazing methods based on the management objectives they were designed to achieve.}

Vegetation standing crop and animal production are the two variables most commonly used to compare continuous stocking with rotational grazing in research studies. ${ }^{2,5}$ However, research has shown that the primary vegetation response to grazing is change in species composition, not changes in net primary production..$^{6-8}$ Vegetation changes that increase the proportion of desirable forage species will increase grazing capacity and the reliability of forage production although net primary production may not increase. The evaluation of grazing strategies needs to consider responses of the total system relative to the management objectives, not just plant and animal production in response to isolated grazing practices.

Both temporal and spatial scales should be considered when evaluating grazing methods. Animal production responds to immediate conditions. However, rangeland restoration may take many years or decades, depending on the climate, soils, and the degree of degradation. On severely degraded arid and semi-arid rangelands, recovery of ecological processes that restore rangeland health may take decades and may initially require reduced stocking levels. Most grazing research has not evaluated long-term changes in species composition on degraded rangelands. 


\section{Grazing Methods}

\section{Key Concept: Grazing strategies should match \\ the unique combination of physical, biotic, and \\ management resources and the specific \\ management objectives of each ranch.}

No two ranches have the same resources or management objectives; therefore, why should they have the same grazing management plans? Grazing plans also change over time as the manager learns and as rangeland vegetation and health change. There is not one unique best-management plan or grazing system "template." A rancher can mix grazing methods, with different grazing methods applied at the same time on different parts of the ranch or on the same area over time. The complexity of grazing methods and management varies greatly across a gradient from continuous fixed stocking to adaptively managed, intensive, rotational grazing. "Intensive" grazing management as used here refers to the intensity of management required, not to the degree of use on forage.

The question a manager needs to ask is this: "Will this management plan enhance progress towards my goals?" Understanding the capabilities and desires of the manager is the first critical ingredient in designing a grazing method that will be successful and sustainable. At a research field day in west Texas during the 1980s, a scientist was presenting information on a grazing system with many pastures per herd and frequent livestock rotation when one of the ranchers commented, "If I had wanted to operate a dairy, I would have bought a dairy!" Obviously, he was not a good candidate for a grazing plan that requires intensive management. Managers should carefully assess their goals and aptitudes before designing a grazing management plan. Fitting a grazing plan to the manager's abilities, interests, and resources is critical to its ultimate success.

\section{Continuous or Season-Long Stocking}

Key Concepts:

- Continuous stocking allows animals to graze selectively with minimal disturbance.

- Continuous stocking provides maximum short term livestock gains.

- Selective grazing for preferred species and areas may cause rangeland deterioration.

- Restoring the health of degraded rangelands is difficult under continuous stocking.

Continuous stocking is the simplest grazing method a rancher can apply. It may be year-long or season-long, and animals have unrestricted access to the entire grazing area throughout the grazing season. Continuous stocking is the grazing method of choice for many ranchers. The following attributes make continuous stocking an attractive method for ranchers:

- It requires minimal management decisions and inputs.

- It focuses the primary grazing management decision on managing stocking level (animal numbers).
- It requires little or no additional investment in infrastructure.

- It produces good short-term animal performance by permitting selective grazing on preferred areas, plant species, and plant parts.

Over the short term, continuous stocking enhances animal production by allowing maximum opportunity for selective grazing with minimal handling disturbance. However, over the long term, it can lead to rangeland degradation and declining animal production. Low stocking densities under continuous stocking allow livestock to repeatedly graze preferred plants and areas while other plants and areas receive little or no use. This stratifies forage quality, which intensifies selective grazing and eventually results in degradation. The primary management options under continuous stocking are to increase or decrease animal numbers (e.g., total grazing pressure) and/or increase fencing and water development or other attractants or herding to change distribution of grazing pressure on the landscape.

Continuous light to moderate stocking can sustain rangeland health if there is little area- or species-selective grazing, though preferred areas (e.g., near shade or water) will still probably suffer. However, it is difficult to improve moderate to severely degraded rangelands with continuous light stocking because these ranges usually have significant problems with area- and species-selective grazing. Continuous stocking does not provide deferment to reduce the detrimental effects of selective grazing. Another disadvantage of continuous stocking is the difficulty of successfully implementing vegetation improvement practices (e.g., range seeding, prescribed burning, and brush control).

\section{Deferred Stocking}

Key Concepts:

- Deferment is a conservation practice for restoring and maintaining rangeland bealth.

- Deferment is not a practice to increase livestock production within a grazing season.

- Deferment applied with other range improvement practices can enhance vegetation response.

- Repeated deferment over a period of years can increase rangeland carrying capacity, if it improves range condition.

Deferred stocking, as used in this paper, includes all grazing methods that provide periodic deferment, either in a systematic rotation or by managerial decision. Deferment is a continuous period without grazing during the growing season that allows preferred plant species to reach reproductive maturity. It may be as short as 60 days or longer than a year, depending on the environment and vegetation. Deferred stocking emphasizes deferring pastures, not rotating livestock. Deferment is a practice that increases populations of desirable species and restores ecosystem processes for rangeland health. It allows closely grazed plants and patches to recover vigor and accumulate biomass. More than 100 years ago, Jared $\mathrm{Smith}^{9}$ recognized the need for proper 
stocking and periodic deferment to maintain healthy rangelands and to improve deteriorated rangelands. Deferment combined with proper stocking is a relatively simple practice that facilitates the restoration and maintenance of rangeland health. It is a conservation practice, not a practice to increase livestock production in the short term.

Deferment is often used to enhance other vegetation improvement practices (e.g., prescribed burning, seeding, and brush management) and specialized wildlife management. The synergism between deferment and other improvement practices frequently produces the greatest benefits derived from a "grazing system."10

The rate of species composition change (i.e., plant succession) is directly related to water and nutrient availability. In arid and semi-arid climates, plant succession progresses slowly and intermittently, only proceeding when environmental conditions are favorable for plant growth, vegetative reproduction, and/or seed production. In low-rainfall areas, it may take decades to significantly increase small populations of desirable plants on severely degraded rangeland. The length of deferment should increase as the amount of precipitation decreases. Plant succession proceeds much more rapidly in high-rainfall regions, unless the lack of a seed source limits it. Rangelands with long-lived woody species will require treatment with chemical and/or mechanical methods, prescribed herbivory, and/or prescribed fire practices to reduce the dominance of woody species and to allow the herbaceous species to increase. Deferred grazing used in combination with these practices enhances their success.

A key to the successful use of deferred grazing is maintaining a relatively low grazing pressure. Stocking levels need to be set low enough to prevent heavy use of grazed pastures, which will help maintain good individual animal performance. The smaller the fraction of the total area that livestock have access to, the shorter the grazing periods must be to maintain grazing pressure at an acceptable level. There is a tradeoff between increasing the duration and frequency of deferment to enhance plant succession and allowing livestock more access to forage to maintain good animal production. Deferment increases the average plant maturity and reduces average forage quality. Successful deferred stocking strikes a balance between the frequency and duration of deferment to enhance range improvement and the frequency and duration of grazing to enhance animal performance. The desired balance will depend on the relative weight given to range improvement and livestock production objectives.

\section{Rotational Stocking}

Key Concept: Rotational stocking is more flexible, has more management variables, requires more intensive adaptive management, and can be managed to meet a wider variety of vegetation and animal management objectives than continuous stocking or deferred stocking.

Rotational stocking rotates livestock through three to many paddocks per herd and uses high stocking density (i.e., livestock have access to one-third or less of the total land area at any point in time). There are four principal components of rotational stocking: 1) stocking level, 2) number of paddocks per herd, 3) length of rest periods, and 4) length of grazing periods. Each component has a wide range of possible values, and a manager using adaptive management may manipulate each of these components within and across years, thus creating an endless number of possible grazing strategies. It is important that a manager using rotational stocking has a good understanding of principles related to the four components because different grazing strategies produce very different plant and animal responses. Success stories for rotational stocking come from ranchers who commit to intensive adaptive management, obtain the requisite knowledge and experience, and design and manage grazing strategies to fit their resources and objectives. They represent a relatively small cohort of ranchers.

Different combinations of the four rotational stocking variables produce different intensities and frequencies of defoliation. Although both intensity (I) and frequency (F) of defoliation are continuous variables, I have classified them as high $(\mathrm{H})$, medium $(\mathrm{M})$, and low $(\mathrm{L})$, allowing nine combinations (e.g., HILF, HIMF, HIHF, MILF, MIMF, MIHF, LILF, LIMF, and LIHF). High-intensity, lowfrequency (HILF) and short-duration grazing (SDG) are terms commonly used without specific definition with respect to the intensity and frequency of defoliation. It is beyond the scope of this paper to examine all possible rotational stocking strategies for many different kinds of rangeland ecosystems. Therefore, a discussion of the strengths and weaknesses of two contrasting frequencies of grazing (high and low), both with high grazing intensity (e.g., an increasing intensity of defoliation), with respect to the stocking level and kind of environment is presented. These two general categories of rotational grazing, high-intensity, low-frequency (HILF) and high-intensity, high-frequency (HIHF), define the opposite ends of a management continuum with respect to frequency of grazing.

High-intensity low-frequency (HILF), as the name implies, has a high-intensity of defoliation and a low frequency of grazing (e.g., long rest periods of 90 days to $>1$ year). In systems with a small number of pastures per herd, long rest periods produce relatively long grazing periods, increasing the intensity of grazing. In systems with a larger number of pastures per herd the grazing periods can be shorter, but the increased stocking density increases the grazing intensity. Reducing the system stocking level can produce MILF or LILF, which improves animal performance. HILF grazing is most applicable for vegetation improvement in low precipitation environments.

High-intensity high-frequency (HIHF) employs short rest periods and very short grazing periods, again with a high intensity of defoliation. Rest periods range from 2 weeks to 6 weeks. Grazing periods are 1 day to 7 days, with 1-day 
grazing periods being optimal. HIHF grazing focuses on increasing animal production and is best suited to high production environments.

Focusing on these two extreme types of rotational grazing, this discussion illustrates vegetation and livestock production responses across the continuum of grazing frequencies and identifies principles that ranchers can use to plan and manage rotational grazing.

\section{HILF Key Concepts:}

- HILF is an effective conservation practice for enhancing plant succession on degraded rangelands (e.g., promoting species composition change and improving rangeland health).

- HILF frequently reduces animal production compared to continuous stocking.

The low frequency of grazing in HILF maximizes range improvement but reduces livestock production compared with continuous stocking at a comparable stocking level. The intensity of forage use during each grazing period depends on the system stocking level, the stocking density, and the length of the grazing periods. To improve animal performance, increase the number of paddocks per herd and shorten the grazing periods while keeping the rest period constant.

Long rest periods produce mature forage, especially with higher precipitation, and increase selective grazing. Many plants initiate and complete their growth cycle during long rest periods without livestock having any opportunity to graze them when forage quality is high. Vegetation at the beginning of a grazing period consists of some high-quality forage and much mature low-quality forage. The result is a high level of diet quality at the beginning of a grazing period followed by declining diet quality and intake as the grazing period progresses. This cycle repeats with each grazing period, causing continual fluctuations in the animal's nutrient intake, reducing animal performance. Reducing system stocking levels improves individual animal gains but reduces total livestock production. Where HILF is desired for rangeland improvement but where livestock production is also a high management priority, strategic supplemental feeding can be used to even out the fluctuations in diet quality and intake. Free-choice supplement feeding allows animals to vary their consumption of supplement based on their nutritional needs. This would be most applicable to stocker operations and can maintain high animal production while promoting rapid range improvement.

Large increases in stocking density can change the spatial distribution of grazing and can cause animals to graze the landscape more uniformly. By increasing the number of paddocks per herd, stocking density can be increased 20 to 50 times, compared with continuous stocking without changing the system stocking level. Ranchers using high stock density have observed significant reductions in area-selective grazing problems. When combined with a low frequency of grazing, this produces significant range improvement. Areas of animal concentration around water and bed grounds recover and become productive, and animals graze more uniformly across the landscape. Significant improvement in grazing distribution can significantly increase grazing capacity.

HILF is more effective for decreasing area-selective grazing than it is species-selective grazing. The high average forage maturity may intensify species-selective grazing. As rangeland improves, the manager may shift management towards shorter rest periods that will maintain rangeland health, but yield better livestock production.

\section{HIHF Key Concepts:}

- $H I H F$ is a practice to maximize livestock production by producing uniform high quality swards and efficient forage utilization.

- HIHF is best suited to highly productive pastures of palatable forage species with long continuous growing seasons.

- HIHF is not a good grazing strategy for arid or semi-arid rangelands or those with significant species-selective grazing problems.

Ideally HIHF uses 1-day grazing periods with very high stock densities to produce a uniform harvest of forage across the entire pasture while leaving adequate residual green biomass to support rapid plant recovery during short rest periods. Short rest periods prevent forage from maturing and present animals with a uniform standing crop characterized by predominantly green leaves with very little stem or dead leaf. Frequent defoliation shifts plant growth towards a greater proportion of leaf and lesser proportions of stem and root. Leaves are consumed before they senesce. Frequent uniform grazing produces a dense, compact, leafy sward structure that allows animals to obtain a large bite size with high nutrient concentration. HIHF can reduce selective grazing; however, it is not an effective method to correct significant species-selective grazing problems in arid and semi-arid ecosystems.

Short grazing and rest periods maintain uniformly high levels of diet quality and prevent the wide swings in diet quality and intake that are characteristic with long rest periods in HILF. HIHF is best suited for humid regions with long growing seasons, high nitrogen availability, and plant species that are adapted to respond quickly following frequent intensive defoliation. Applied to rangelands with limited water and/or nutrients or extreme temperatures, HIHF does not provide adequate recovery time and can collapse forage growth. Plants in arid environments are less tolerant of intensive defoliation and require longer recovery periods than are plants in highly productive humid environments.

Successful use of HIHF requires suitable ecosystems and adaptive management. Fixed grazing schedules and stocking 
rates are not recommended. Managing HIHF requires knowledge and experience to make frequent (e.g., daily) adjustments in response to changing environmental, biotic, and management factors. Short grazing and rest periods in HIHF increase animal production by maximizing the efficiency of nutrient harvest. HIHF is not an effective range improvement strategy because intensive defoliation and short rest periods do not provide deferment to promote plant succession.

\section{Mixed Grazing Methods}

\section{Key Concepts:}

- There is not one "best grazing management" practice.

- Grazing strategies are tools that a rancher can use to achieve specific vegetation management and livestock production objectives.

- Successful managers understand the condition and potential of their rangelands and design grazing programs that combine grazing methods to achieve their management objectives.

From the proceeding discussion, you may correctly conclude that there is no ideal grazing method. Each method has advantages and disadvantages. This makes it crucial that managers understand the current condition and productive potential of their rangelands and the plant and livestock responses to different grazing methods. A ranch plan can incorporate all grazing methods, either simultaneously or sequentially. Degraded pastures need grazing strategies to promote range improvement. Healthy rangelands can use grazing strategies to improve livestock production and maintain rangeland health. Grazing strategies can also meet a variety of other purposes, as illustrated by other papers in this issue.

Creative managers combine different grazing methods with flexible management. For example, periods of aboveaverage forage production allow deferment of additional pastures and application of practices such as prescribed burning. On the other hand, during drought, pastures scheduled for deferment can be grazed to maintain livestock production. Decision deferment can be applied within HIHF by skipping pastures during rotation cycles. The number of pastures per herd can be changed either by changing the number of herds or by changing the number of pastures. Pasture size and number can be changed on a daily basis using temporary electric fences. These are just a few of the possibilities for adapting management to meet management objectives under changing conditions.

\section{Summary}

Continuous stocking is not an effective method for restoring degraded rangelands. Deferment combined with moderate stocking enhances restoration of deteriorated rangelands. Deferment applied in conjunction with other range improvement practices can produce synergistic responses for rangeland improvement. Deferment is primarily a conservation practice not an animal production practice.
Rotational stocking requires adaptive management in order to be successful. Rotational stocking at light to moderate stocking with frequent long rest periods (e.g., HILF) maximizes range improvement through promoting plant succession but reduces livestock production compared with continuous grazing at a similar stocking level. Rotational stocking during the growing season with HIHF will maximize livestock production, but it is only sustainable on pastures with high water and nitrogen availability where plant species are adapted to frequent close defoliation.

Successful managers identify their management goals, understand their management preferences, know the principles governing plant and animal responses to different grazing methods, and use adaptive management to develop unique grazing plans suited to their ranch. Instead of research designed to identify "the best grazing method," researchers need to identify and quantify grazing processes and principles that will support adaptive grazing management.

\section{Acknowledgments}

The author wishes to thank Richard Teague, Ray Hinnant, Rod Heitschmidt, David Briske, Roy Roath, Tim Steffens, Leonard Jolley, and three anonymous reviewers for their constructive reviews of drafts of this manuscript. The author assumes responsibility for all opinions expressed in this paper.

\section{References}

1. Voisin, A. 1959. Grass productivity. Washington, DC, USA: Island Press. 353 p.

2. Briske, D. D., J. D. Derner, J. R. Brown, S. D. Fuhlendorf, W. R. Teague, K. M. Havstad, R. L. Gillen, A. J. Ash, And W. D. Willms. 2008. Rotational grazing on rangelands: reconciliation of perception and experimental evidence. Rangeland Ecology and Management 61:3-17.

3. Gordon, K. 2008. Is rotational better? Beef. Available at: http://beefmagazine.com/pasture-range/grazing-programs/ 0701-producers-scientists-found-grazing/index.html. Accessed October 2009.

4. Price, F. 2009. RC Factor. Grassroots, May-June 2009, Texas Section, Society for Range Management. Available at: http:// texas.rangelands.org/. Accessed October 2009.

5. Van Poolen, H. W., and J. R. Lacey. 1979. Herbage response to grazing systems and stocking intensities. Journal of Range Management 32:250-253.

6. Dwyer, D. D., J. C. Buckhouse, and W. S. Huey. 1984. Impacts of grazing intensity and specialized grazing systems on the use and value of rangeland: summary and recommendations. In: Developing strategies for rangeland management. Boulder, CO, USA: National Research Council, National Academy of Sciences, Westview Press. p. 867-884.

7. Frost, W. E., and E. L. Smith. 1991. Biomass productivity and range condition on range sites in southern Arizona. Journal of Range Management 44:64-67. 
8. Liang, Y., G. Han, H. Zhou, M. Zhao, H. A. Snyman, D. Shan, and K. M. Havstad. 2009. Grazing intensity on vegetation dynamics of a typical steppe in northern Inner Mongolia. Rangeland Ecology and Management 62:328-336.

9. Sмiтh, J. G. 1895. Forage conditions of the Prairie Region. USDA Yearbook of Agriculture-1895. Washington, DC, USA: US Government Printing Office. p. 309-324.
10. Heady, H. F. 1961. Continuous vs. specialized grazing systems: a review and application to California annual type. Journal of Range Management 14:182-193.

Author is Professor, Dept of Ecosystem Science and Management, Texas AE'M University, College Station, TX 77843, USA, m-kothmann@tamu.edu.

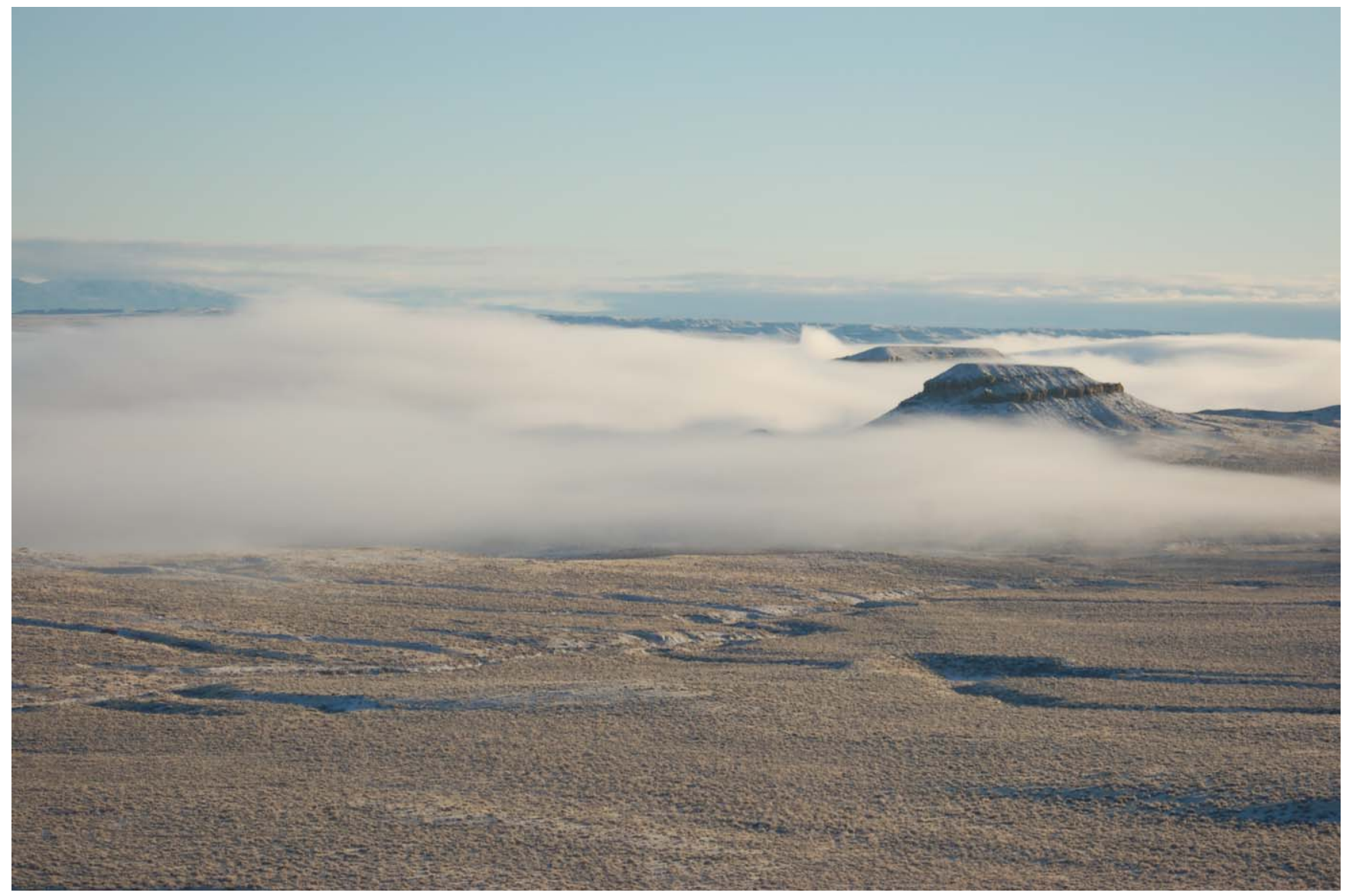

Even small amounts of precipitation, in this case fog, can increase the diversity in forage availability and animal distribution in arid landscapes (Wind River, WY, USA). Photo courtesy of Bob Budd. 